\title{
DIFFERENTIATION OF FIVE SPECIES OF MEGACHILE (HYMENOPTERA: MEGACHILIDAE), BASED ON WING SHAPE
}

\author{
Shahram Falamarzi ${ }^{1}$ \\ Behzad Habibpour ${ }^{1 *}$ \\ Mohammad S. Mossadegh ${ }^{1}$ \\ Alireza Monfared² \\ 'Department of Plant Protection, College of Agriculture, Shahid Charman University \\ of Ahvaz, Ahvaz, Iran \\ ²Department of Plant Protection, Faculty of Agriculture, Yasouj University, Yasouj, \\ Iran \\ * corresponding author: habibpour_b@scu.ac.ir \\ Received: 26 April 2016; accepted: 5 July 2016
}

Abstract

In the present work we used landmark-based geometric morphometrics to compare the wing shapes of five species of Megachile (belonging to three subgenera) to confirm whether this technique may be used reliably for differentiation of this group. Analyses of wing shape by the use of principal component analysis (PCA), and canonical variate analysis (CVA) led to a clear differentiation among species. We found a close phenotypic similarity in wing shape between M. albisecta (belonging to the subgenus Creightonella) and M. picicornis (belonging to the subgenus Eutricharaea). According to the results of UPGMA, a higher degree of divergence between M. farinosa (belonging to the subgenus Pseudomegachile) and species belonging to other subgenera, was detected. The results of a cross-validation test indicated that geometric morphometrics is an effective technique to use for distinguishing between Megachile species. The reliability rate of this technique was between $85.71-100 \%$. Using only two submarginal cell landmarks for generating shape variables, the cross-validation test correctly assigned individuals to their respective species, with a $92.85-100 \%$ reliability rate. Significant differences in wing size were obtained among the analysed species.

Keywords: geometric morphometrics, Megachile, species differentiation, wing shape

\section{INTRODUCTION}

Megachilidae with more than 4093 described species is the second-largest family of the bees in the world (Michener, 2007; Ascher \& Pickering, 2015). These solitary bees include many pollinators of natural, urban, and agricultural vegetation (Bohart, 1972; Michener, 2007; Pitts-Singer \& Cane, 2011). Megachile is a cosmopolitan genus of this family, containing more than 2000 species and 58 currently recognised subgenera, with a fossil record from Dominican amber (Michener, 2007). Many species of this genus are key pollinators of flowering crops and plants (Sheffield et al., 2011).

The taxonomy of the Megachile is a matter of discussion. The number of genera or subgenera recognised in Megachile is controversial (Michener, 2007). Gonzalez (2008) examined the subgenera and suggested a new classification schema using phylogenetic framework for the genus. He explored the relationship of the subgenera of Megachile by conducting a cladistic analysis on external morphological characters of the adults. Identification keys of Megachile species, particularly females, are constructed based on the mandibular teeth. In some specimens, using this character poses difficulties, such as distinguishing the shape and even number of teeth (Sheffield et al., 2011). These problems highlight the need for applying alternative methods to make clear the classification of this group. Clarification of the taxonomic pattern in these bees can be the subject of molecular research. However, in many cases, especially within dried specimens, we cannot use molecular techniques. Recent developments in geometric morphometrics explor- 


\section{FHlHMARll Et f hl. _Differentiation of Megachile based on wing shape -}

atory-approaches, generate new perspectives for the assessment of morphological characters in this taxonomic matter (Baylac, Villemant, \& Simbolotti, 2003).

Geometric morphometrics are the new way of detecting shape variation and covariation of shape with other factors or variables (Bookstein, 1991). These methods allow a rigorous quantification of morphological structure shapes based on Cartesian coordinates, after removing the effects of all nonshape variation due to position, scale, and rotation (Adams, Slice, \& Rolf, 2004). Since the insect wings are rigidly articulated structures they have become an ideal subject for geometric morphometrics studies (Pavlinov, 2001). Wings are often morphologically taxonspecific and show many methodological merits in comparison with other organs (De Meulemeester et al., 2012).

To date, wing geometric morphometrics have been extensively used to resolve the taxonomic dilemma of some species groups. Morphological analyses help with bee identification by defining and extracting homologous landmarks relevant and discriminatory features from the wing images, so that bees can be classified. Geometric morphometrics have been employed successfully to discriminate pollinator bees (Tofilski, 2008; Gerula et al., 2009; Francoy et al., 2009; Francoy, Franco, \& Roubik, 2012; Miguel et al., 2011; Oleksa \& Tofilski, 2014).

Geometric morphometrics techniques have been used in only a few publications for Megachilids. By using the relative warps, PCA graphs, and UPGMA trees obtained from wing shape differences, Güler, Aytekin, \& Cagatay (2006) recognised the classificatory plan in different taxon of Megachilidae. Williams \& Goodell (2000) by combining geometric morphometrics methods and phylogenetic comparisons, examined the relationship between the shape of the mandible and material utilised in nest constructing by five Osmia Panzer species.

In Iran, geometric morphometric studies have recently been carried out on bees belonging to the genus Apis Linnaeus (Kandemir et al., 2009; Dolati, Nazemi Rafie, \& Khalesro, 2013; Nazemi Rafie, Mohamadi, \& Teimory, 2014).
Since there is no published information on wing geometric morphometrics of Megachile species, we conducted a comparative study among five species belonging to three subgenera of Megachile including Pseudomegachile, Eutricharaea, and Creightonella (M. farinosa belonging to the subgenus Pseudomegachile; M. albisecta belonging to the subgenus Creightonella; $M$. anatolica, M. minutissima, and M. picicornis belonging to the subgenus Eutricharaea). We
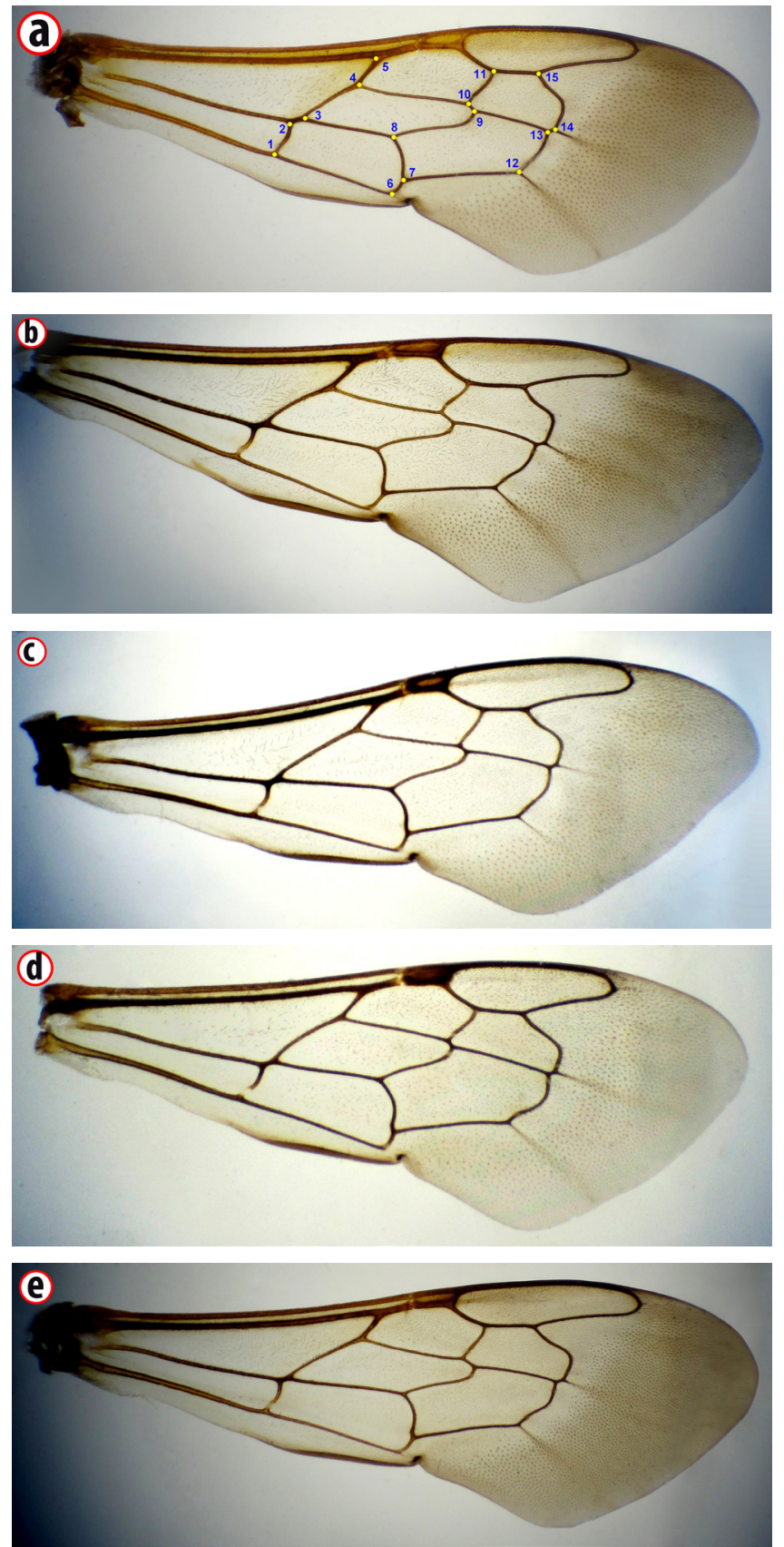

Fig. 1. Right forewings of five species of Megachile. (a) Wing of Megachile farinosa with the 15 landmarks selected for geometric morphometric analysis (b) Wing of M. albisecta (c) Wing of M. anatolica (d) Wing of M. minutissima (e) wing of M. picicornis. 
Table 1

Specimen's number of each species included in the analysis

\begin{tabular}{ccc}
\hline Species & Subgenus & Number \\
\hline Megachile albisecta Klug, 1817 & Creightonella & 14 \\
Megachile anatolica Rebmann, 1968 & Eutricharaea & 17 \\
Megachile farinosa Smith, 1853 & Pseudomegachile & 21 \\
Megachile minutissima Radoszkowski, 1876 & Eutricharaea & 20 \\
Megachile picicornis Morawitz, 1853 & Eutricharaea & 21 \\
\hline
\end{tabular}

examined the forewing shape of these species to determine if this type of information is sufficient to discriminate between the species.

\section{MATERIAL AND METHODS}

Ninety-three female specimens of the genus Megachile (Tab. 1) were collected from Fars Province, Iran in 2013 and 2014. The right forewings (Fig.1a-e) of each bee were removed and mounted onto a microscope slide and photographed digitally with a camera attached to a stereomicroscope. Fifteen landmarks were plotted at the intersections of the wing veins (Fig. 1a) using TpsDig2.16 software (Rohlf, 2010). For future comparisons, wing photographs of all specimens are available as supplementary online information. The coordinates of landmarks were superimposed using a generalised least square algorithm in Morphol 1.06b software (Klingenberg, 2011). All of statistical analyses (except the Tukey test on wing centroid size, creating UPGMA and Forward stepwise discriminant function analysis) were performed in Morpho] software. We used a One-way analysis of variance (ANOVA) test on wing centroid size, to determine the variation in wing size among different species. The significance of the centroid size pairwise differences among species was tested through the Tukey HSD test and visualised using PAST software (Fig. 2). A multivariate analysis of variance (MANOVA) was used to test the significance of the wing shape differences among species. The shape variations of the wings among species were explicitly based on PCA and CVA. Further statistical computations including Mahalanobis distances, and discriminant function analyses (DFA), were conducted to discriminate between species. The percentages of correct classifications were calculated using the leave-one-out cross-validation procedure. Forward stepwise discriminant function analysis (tolerance $=0.01 ; F$ to enter $=1.0$ ) was used to determine classification functions (Statistica ver. 10.0, StatSoft 2011). The phenetic relationships among species were estimated by UPGMA cluster analysis. Average Mahalanobis distances were used in cluster analysis for construction of a UPGMA dendrogram by PAST program (Hammer, Harper, \& Ryan, 2001).

We carried out morphometric analyses on two data sets. The first analysis was based on 15 landmarks defined by the intersections of the wing veins and the second data set resulted from two submarginal cell landmarks (including $4,5,9,10,11,13,14$, and 15). From this analysis only, cross-validation procedure results were prepared.

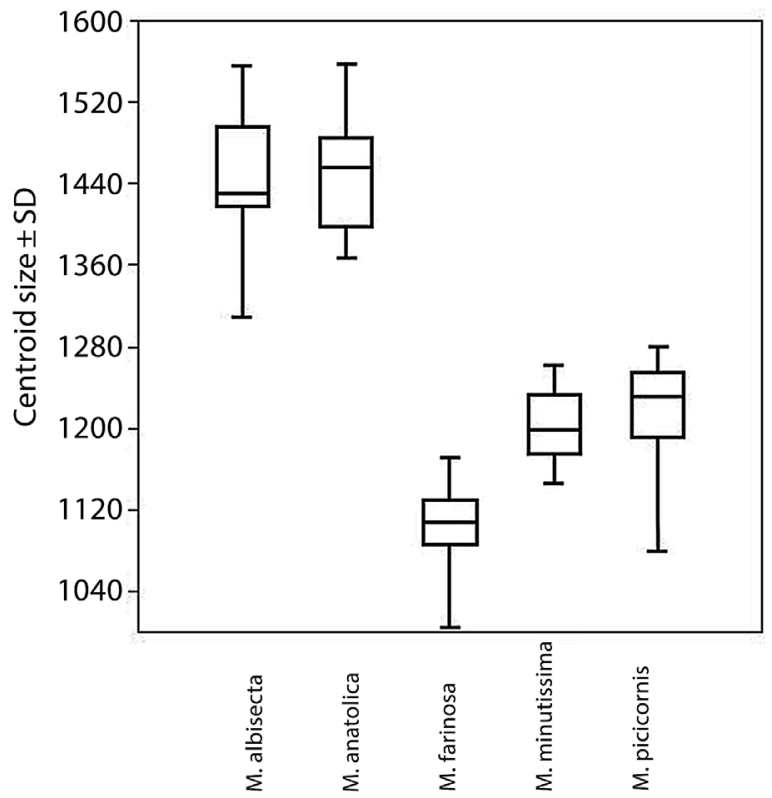

Fig. 2. Centroid size of species of Megachile with the mean, standard error and standard deviation illustrating variation in wing size 


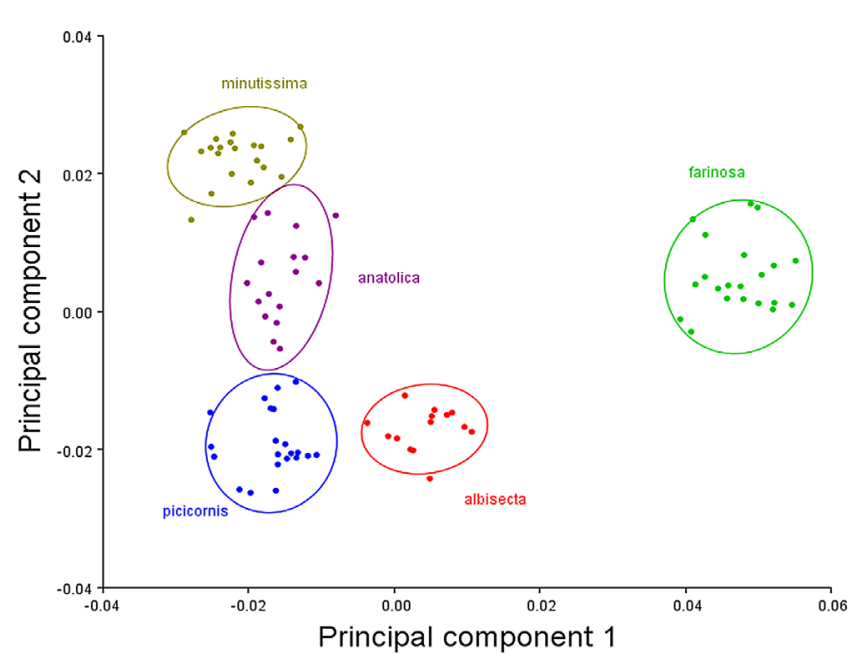

Fig. 3. Distribution of the Megachile specimens along the first two principal components based on 15 landmark's data set

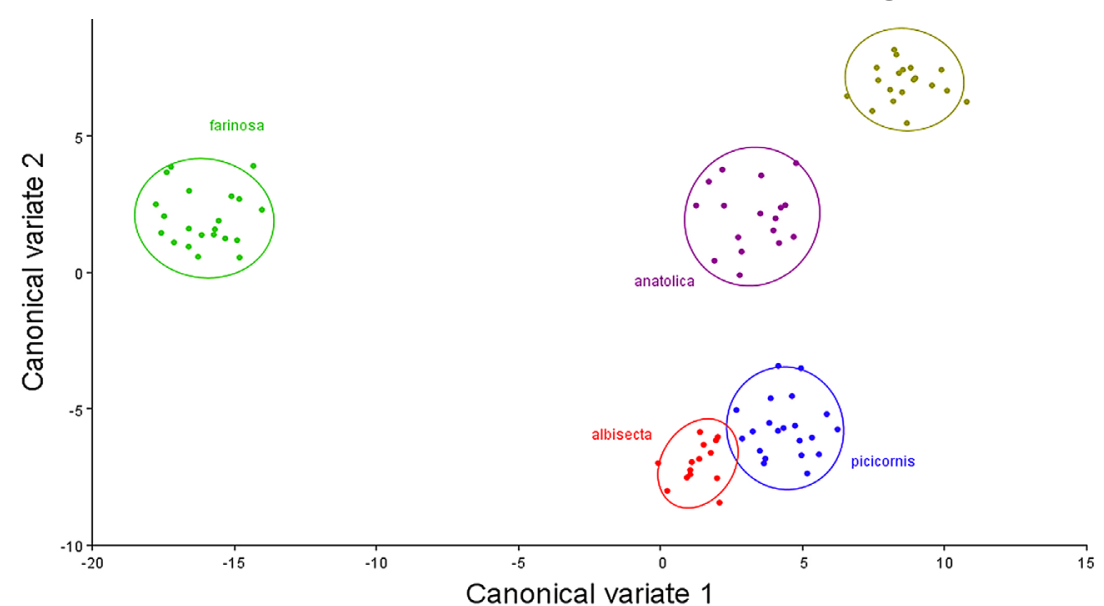

Fig. 4. Distribution of the Megachile specimens along the first two canonical variates based on 15 landmark's data set.

\section{RESULTS}

Analyses on the data set based on 15 landmarks were defined by the intersections of the wing veins:

A significant size variation $\left(F_{4,88}=175.9\right.$, $P<0.0001$ ) was found among species. The Tukey HSD test showed a significant difference among all species pair comparisons except M. minutissima / M. picicornis and M. anatolica / M. albisecta pairs (Fig. 2).

The principle component analysis of the Cartesian coordinates extracted from the wings of the five species gave nine eigenvalues greater than one, which explained $94.942 \%$ of the variation among the species. In the PCA rep- resentation (Fig. 3), the first two axes explain $50.87 \%$ and $18.46 \%$, of the variation, respectively. Different species did not show overlap in the scatterplot of the first two principal components. Species belonging to Eutricharaea and Creightonella subgenera clustered nеar each other but species of $M$. farinosa belonging to the Pseudomegachile subgenus occupy a distinct region.

The canonical variate analysis revealed 4 canonical variates, of which the first three canonical axes accounted for $66.65 \%, 22.45 \%$ and $7.50 \%$ of the total shape variation, respectively, and $96.61 \%$ overall. The canonical variate analysis for the wing shape (Fig. 4) shows a good discrimination of each species. Specimens of $M$. farinosa were separated in a distinct cluster while interestingly, specimens of M. picicornis belonging to the subgenus Eutricharaea were closer to the individuals of $M$. albisecta belonging to the subgenus Creightonella than to other species of the subgenus Eutricharaea.

To explore the relationships among the species, pairwise Mahalanobis distances were calculated (Tab. 2). The scores of the Mahalanobis distances ranged from 8.5782 (M. albisecta vs. M. picicornis) to 25.2687 (M. farinosa vs. M. minutissima). Based on the Mahalanobis distances, the largest difference was observed between $M$. farinosa and $M$. minutissima, whereas the lowest Mahalanobis distance was found between M. albisecta and $M$. picicornis, as suggested by their close position in the scatterplot of the scores on the first two canonical variates.

According to the discriminant analysis results, all specimens were correctly classified $100 \%$ of the time. The efficacy of classifying individual specimens based on landmark configurations was explored using cross-validation tests on discriminant function analyses of species pairs. The cross-validated reclassification accuracy based on the Mahalanobis distances ranged from 85.71 to $100 \%$ among the species (Tab. 3). 
Table 2

Mahalanobis Square distances between five species of Megachile

\begin{tabular}{ccccc}
\hline & M. albisecta & M. anatolica & M. farinosa & M. minutissima \\
\hline M. anatolica & 12.9469 & & & \\
M. farinosa & 20.2068 & 20.2299 & & \\
M. minutissima & 16.3013 & 11.0142 & 25.2687 & \\
M. picicornis & 8.5782 & 9.9617 & 22.0444 & 14.2263 \\
\hline
\end{tabular}

Table 3

Results of the discriminant analyses performed on the wing configuration (15 landmarks) according to the leave-one-out cross-validation test. Percent classifications are in parentheses; $\mathrm{N}$ denotes the number of species

\begin{tabular}{ccccccc}
\hline & M. albisecta & M. anatolica & M. farinosa & M. minutissima & M. picicornis & N \\
\hline M. albisecta & $12(85.71 \%)$ & 0 & 0 & 0 & 2 & 14 \\
M. anatolica & 0 & $15(88.23 \%)$ & 0 & 2 & 0 & 17 \\
M. farinosa & 0 & 0 & $21(100 \%)$ & 0 & 0 & 21 \\
M. minutissima & 0 & 1 & 0 & $19(95 \%)$ & 0 & 20 \\
M. picicornis & 1 & 1 & 0 & 0 & $19(90.47 \%)$ & 21 \\
\hline
\end{tabular}

In the cross-validation test, all specimens were correctly assigned to their species, except 7 out of 93 cases which were misclassified in different species: two M. albisecta were identified as M. picicornis, two M. anatolica as M. minutissima, one $M$. minutissima as $M$. anatolica, one $M$. picicornis as M. albisecta, and one M. picicornis as M. anatolica.

For creating classification function, coordinates of the 15 landmarks were determined for each specimen and the average configurations were calculated (Tab. 4). The average configuration superimposed on the reference configuration. After superimposition, 23 of 30 variables were selected for the discrimination (Tab. 5). Using classification functions, we can classify an unknown specimen to one of the five species. The superimposed landmarks should be taken together with the discrimination functions to calculate the discriminant score for each species. The coefficients of classification function should be used to multiply the scores of each case on the proper discriminator variables. Then, the products should be added up and the constant value should be added. As a result, the case would have received five discriminant scores.
The specimen should be assigned to the species for which it has the largest calculated discriminant score (Brown \& Wicker 2000; Gerula et al. 2009).

The Unweighted Pair Group Method with Arithmetic Mean (UPGMA) cluster analysis of the squared Mahalanobis distances computed from wing shape variables, clustered M. albisecta with
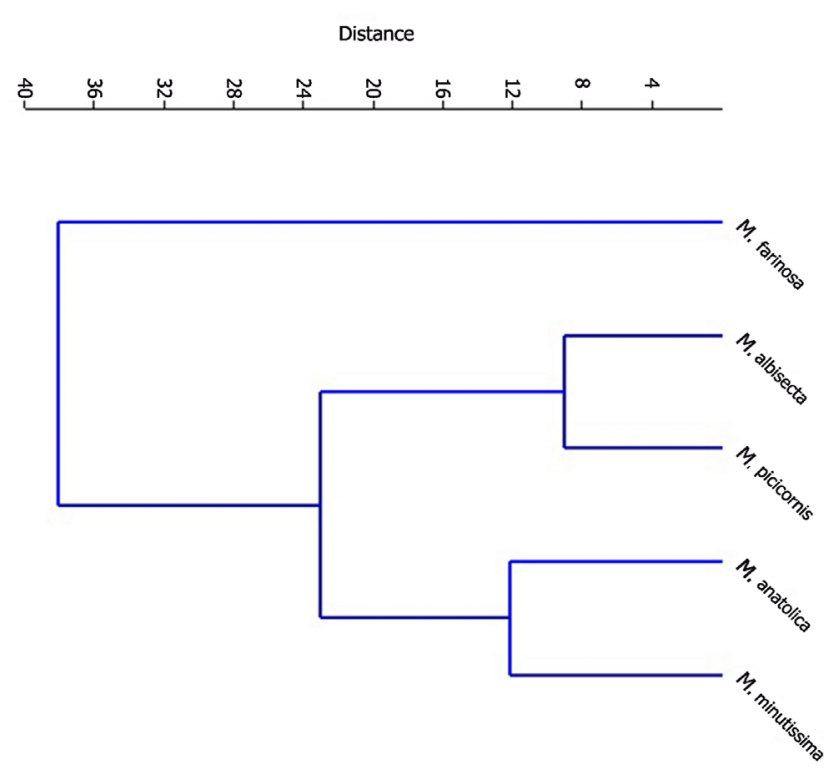

Fig. 5. UPGMA phenogram based on the squared Mahalanobis distances between Megachile species. 


\section{FHl[MMARll Et Hl. _Differentiation of Megachile based on wing shape}

Table 4

Mean configuration of the 15 landmarks coordinates for five Megachile species

\begin{tabular}{|c|c|c|c|c|c|c|}
\hline LM & M. albisecta & M. anatolica & M. farinosa & M. minutissima & M. picicornis & $\begin{array}{l}\text { All } 5 \text { species } \\
\text { (reference con- } \\
\text { figuration) }\end{array}$ \\
\hline $1 X$ & -0.39590063 & -0.40666403 & -0.39452198 & -0.40461041 & -0.40009224 & -0.40061895 \\
\hline $1 Y$ & -0.05569811 & -0.05452747 & -0.05303075 & -0.06177397 & -0.05768844 & -0.05654008 \\
\hline $2 x$ & -0.35835951 & -0.36420295 & -0.34953870 & -0.34955671 & -0.36217886 & -0.35661964 \\
\hline $2 Y$ & 0.01259464 & 0.01455039 & 0.02117334 & 0.01011591 & 0.01481911 & 0.01496665 \\
\hline $3 x$ & -0.32614237 & -0.33224517 & -0.31329671 & -0.31672532 & -0.33425249 & -0.32435764 \\
\hline $3 Y$ & 0.02599752 & 0.02785671 & 0.03275765 & 0.02440053 & 0.02462208 & 0.02734525 \\
\hline $4 X$ & -0.17149612 & -0.14056669 & -0.16484306 & -0.16136266 & -0.15675655 & -0.15886111 \\
\hline $4 Y$ & 0.10768218 & 0.12137360 & 0.10897135 & 0.11882668 & 0.11165488 & 0.11387374 \\
\hline $5 x$ & -0.11621119 & -0.09895066 & -0.11616031 & -0.11412268 & -0.11506167 & -0.11235189 \\
\hline $5 Y$ & 0.16897691 & 0.17349851 & 0.17113894 & 0.17672403 & 0.16447293 & 0.17106523 \\
\hline $6 x$ & -0.08093946 & -0.07611280 & -0.10553140 & -0.06812234 & -0.07307428 & -0.08122530 \\
\hline $6 Y$ & -0.17746581 & -0.18513592 & -0.17354163 & -0.19472479 & -0.18014968 & -0.18254584 \\
\hline $7 x$ & -0.04493084 & -0.04768773 & -0.07416086 & -0.04441340 & -0.03911791 & -0.05072160 \\
\hline $7 Y$ & -0.14193224 & -0.14838195 & -0.14011921 & -0.15631928 & -0.14615716 & -0.14697699 \\
\hline $8 x$ & -0.06357293 & -0.06797021 & -0.07787132 & -0.06529016 & -0.05925981 & -0.06702443 \\
\hline $8 Y$ & -0.03677787 & -0.03660034 & -0.03663090 & -0.03373603 & -0.03480942 & -0.03569914 \\
\hline $9 x$ & 0.11914697 & 0.11734579 & 0.12862004 & 0.10719295 & 0.11613185 & 0.11780427 \\
\hline $9 Y$ & 0.02276003 & 0.02660528 & 0.02034885 & 0.03377026 & 0.02189687 & 0.02516711 \\
\hline $10 x$ & 0.09269409 & 0.09962248 & 0.10994605 & 0.09186446 & 0.09262834 & 0.09775644 \\
\hline $10 Y$ & 0.04918700 & 0.04859426 & 0.04367070 & 0.05556885 & 0.04492188 & 0.04834373 \\
\hline $11 X$ & 0.16347073 & 0.16762396 & 0.18216267 & 0.15793457 & 0.15600183 & 0.16570935 \\
\hline $11 Y$ & 0.11804178 & 0.12318956 & 0.11846377 & 0.12779506 & 0.12221400 & 0.12227444 \\
\hline $12 x$ & 0.22240059 & 0.21974383 & 0.23001110 & 0.22911361 & 0.22005758 & 0.22464104 \\
\hline $12 Y$ & -0.13414903 & -0.14276889 & -0.14093735 & -0.14426520 & -0.13141223 & -0.13891427 \\
\hline $13 x$ & 0.32208914 & 0.31376235 & 0.31511962 & 0.32394201 & 0.32689200 & 0.32065332 \\
\hline $13 Y$ & -0.03497812 & -0.04119457 & -0.04252044 & -0.03884812 & -0.03525656 & -0.03887373 \\
\hline $14 X$ & 0.34555054 & 0.33523505 & 0.33077524 & 0.34418405 & 0.34798691 & 0.34078133 \\
\hline $14 Y$ & -0.03069968 & -0.03437167 & -0.03754848 & -0.03142229 & -0.02914741 & -0.03291152 \\
\hline $15 X$ & 0.29220099 & 0.28106678 & 0.29928963 & 0.26997202 & 0.28009531 & 0.28443483 \\
\hline $15 Y$ & 0.10646080 & 0.10731250 & 0.10780415 & 0.11388835 & 0.11001915 & 0.10942544 \\
\hline
\end{tabular}

M. picicornis and M. anatolica with M. minutissima in the same branch, while M. farinosa was the most divergent species in a very distinctive clade (Fig. 5).

\section{Analyses based on 8 landmarks of two sub-} marginal cells:

The landmarks 13 and 14 related to the second submarginal cell are determined as having the two highest relative contributions to the variation in shape of the forewing (with values of SS=0.28433 and 0.22756, respectively). For this reason, we performed another analysis on the data set resulted from two submarginal cell landmarks. The cross-validated reclassification accuracy based on the Mahalanobis distances, ranged from 92.85 to $100 \%$ among the species (Tab. 6). In the cross-validation test, all specimens were correctly assigned to their species, except 3 out of 93 cases which were misclassified as different species: one $M$. albisecta was identified as $M$. picicornis, one $M$. minutissima as M. anatolica, and one $M$. picicornis as M. anatolica.

\section{DISCUSSION}

In the present study, a landmark-based geometric morphometrics technique was applied to study the wing shape variables among five species of Megachile belonging to three subgenera. This is the first study which investigated the 
Table 5

Classification functions for discrimination of five Megachile species

\begin{tabular}{cccccc}
\hline Variable & M. albisecta & M. anatolica & M. farinosa & M. minutissima & M. picicornis \\
\hline $7 X$ & -441689 & -445685 & -453778 & -445444 & -442449 \\
$12 Y$ & -519675 & -519197 & -519572 & -520835 & -517903 \\
$2 X$ & -853382 & -851816 & -859156 & -849114 & -851411 \\
$6 X$ & -642077 & -636927 & -641505 & -636714 & -639310 \\
$2 Y$ & -63125 & -59012 & -53579 & -61993 & -60406 \\
$14 X$ & 201261 & 199067 & 194886 & 202572 & 200262 \\
$7 Y$ & -385723 & -384959 & -387482 & -387975 & -386068 \\
$5 X$ & -325613 & -324773 & -330445 & -323721 & -324310 \\
$4 X$ & -759829 & -756801 & -761410 & -756633 & -757048 \\
$10 X$ & -232560 & -230713 & -232134 & -229380 & -231454 \\
$13 Y$ & -627588 & -629784 & -634570 & -629863 & -628680 \\
$8 X$ & -441664 & -439438 & -444281 & -437949 & -439302 \\
$13 X$ & 49830 & 47670 & 45002 & 48879 & 50265 \\
$9 Y$ & 137157 & 140188 & 141063 & 140245 & 137755 \\
$12 X$ & -25792 & -26484 & -27281 & -25178 & -26974 \\
$15 X$ & 102619 & 100677 & 100510 & 101506 & 101834 \\
$10 Y$ & -215538 & -215247 & -220479 & -213654 & -215113 \\
$5 Y$ & 57510 & 57273 & 56446 & 58803 & 56605 \\
$8 Y$ & -201140 & -200786 & -203160 & -199077 & -199385 \\
$3 Y$ & 330901 & 329096 & 327811 & 333076 & 331344 \\
$1 X$ & -876509 & -874317 & -877851 & -875799 & -874367 \\
$3 X$ & -832005 & -829238 & -832280 & -829884 & -829767 \\
$6 Y$ & -408332 & -406293 & -407166 & -406093 & -406162 \\
Constant & -759912 & -754236 & -759713 & -757066 & -755430 \\
\hline
\end{tabular}

Table 6

Results of the discriminant analyses performed on the wing configuration (8 landmarks) according to the leave-one-out cross-validation test. Percent classifications are in parentheses; $\mathrm{N}$ denotes the number of species

\begin{tabular}{ccccccc}
\hline & M. albisecta & M. anatolica & M. farinosa & M. minutissima & M. picicornis & $N$ \\
\hline M. albisecta & $13(92.85 \%)$ & 0 & 0 & 0 & 1 & 14 \\
M. anatolica & 0 & $17(100 \%)$ & 0 & 0 & 0 & 17 \\
M. farinosa & 0 & 0 & $21(100 \%)$ & 0 & 0 & 21 \\
M. minutissima & 0 & 1 & 0 & $19(95 \%)$ & 0 & 20 \\
M. picicornis & 0 & 1 & 0 & 0 & $20(95.23 \%)$ & 21 \\
\hline
\end{tabular}

systematic relationships within this genus by a subgenus Eutricharaea. These two species had statistical quantification of the wing shape dif- the most similar wing shape morphology. It was ferences.

A principle component analysis of wing shape based on dataset of 15 landmarks was appropriate for discriminating between different species. A canonical variate analysis of wing shapes showed that species can be separated clearly from each other. However, we found a very close phenotypic similarity of wing geometry between M. albisecta belonging to the subgenus Creightonella and M. picicornis belonging to the seen by PCA, CVA, and UPGMA graphs that there was a higher phenetic distance of the $M$. farinosa belonging to subgenus Pseudomegachile from the other species. In a recent study by Gonzalez (2008), Pseudomegachile was considered as a subgenus of the distinct genus Chalicodoma. According to his study, Chalicodoma is monophyletic as is the sister group of Megachile.

For elucidating the role of wing geometry in taxonomy of Megachile, we can accentuate the 
shape of wing cells, particularly the submarginal cell, as morphological markers for discriminating between species. In the Pseudomegachile subgenus, the first submarginal cell is longer than the second ones. Because of the obvious difference in size of the two submarginal cells of M. farinosa, we propose that the most informative cells for discrimination of this species are submarginal cells. By using only two submarginal cell landmarks for generating shape variables, the cross-validation test correctly assigned individuals to their respective species, with a reliability rate between $92.85-100 \%$.

Current identification keys of Megachile females are based on mandibular dentition. Sometimes in old specimens, number and shape of mandibular teeth are difficult to distinguish. We had a similar problem identifying specimens with the mandibles closed or dirty specimens (Sheffield et al., 2011). Therefore, we tried to use an alternative classification method in which dentition is not largely relied on. It seems that morphological difference in forewing shape could be indicative of the correct systematic relationships among the species of Megachile.

Assessing the decline of the pollinator bees is one of the vital priorities considered by pollination experts. Such an assessment is needed to provide a detailed analysis of the pollinator diversity status and to provide information suitable for enhancing their conservation. Reliable assessment depends on the exact taxonomic identification of these insects. Bees taxonomic capacity is currently inadequate and improvement is critical for their conservation (Eardley et al., 2006). Because there are few taxonomic experts and because of conventional taxonomy, the identification of Megachile using geometric morphometrics can help the recognition of these important pollinators to be made more quickly.

This study validates the use of wing traits for Megachile species identification. Geometric morphometrics provides a powerful tool to face the insufficiency of taxonomic experts and data that will help in the correct identification of these important pollinators based only on wing geometry. Exact recognition will promote studies on their ecology and will help focus conservation efforts on these pollinators.

\section{ACKNOWLEDGEMENTS}

The authors wish to thank the Plant Protection Department, Faculty of Agriculture, University of Shahid Chamran Ahvaz for financial and technical assistance. We would like to thank the two anonymous reviewers for their constructive comments. We are grateful to Ehsan Moradi for assistance in collecting materials, and to Lorena Andrade Nunes, Dr. Adam Tofilski and Heng lin yeap for their help with the different softwares. We would also like to thank Mohammad Falamarzi for editing the photos.

\section{REFERENCES}

Adams, D. C., Slice, D. E., \& Rolf, F. J. (2004). Geometric morphometrics: ten years of progress following the 'revolution'. Italian Journal of Zoology, 77, 5-16.

Ascher, J. S., \& Pickering, J. (2015). Discover Life bee species guide and world checklist (Hymenoptera: Apoidea: Anthophila). Available at: http://www.discoverlife.org/mp/20q?guide=Apoidea_species.

Baylac, M., Villemant, C., \& Simbolotti, G. (2003). Combining geometric morphometrics with pattern recognition for the investigation of species complexes. Biological Journal of the Linnean Society, 801), 8998. DOl: 10.1046/j.1095-8312.2003.00221.x

Bohart, G. E. (1972). Management of wild bees for the pollination of crops. Annual Review of Entomology, 17,287-312.

Bookstein, F. L. (1991). Morphometric tools for landmark data. Cambridge University Press, Cambridge. $435 \mathrm{pp}$.

Brown, M. T., \& Wicker, L. R. (2000). Discriminant analysis. In: Tinsley H. E. A. Brown S. D. (Eds.), Handbook of applied multivariate statistics and mathematical modeling. Academic Press, San Diego, California: 209-235. 
De Meulemeester, T., Michez, D., Aytekin, A. M., Danforth, B. N. (2012). Taxonomic affinity of halictid bee fossils (Hymenoptera: Anthophila) based on geometric morphometrics analyses of wing shape. Journal of Systematic Palaeontology, 1044), 755-764. DOl: 10.1080/14772019.2011.628701

Dolati, L., Nazemi Rafie, J., \& Khalesro, H. (2013). Landmark-based morphometric study in the fore and hind wings of an Iranian race of European honeybee (Apis mellifera meda). Journal of Apicultural Science, 57(2), 187-197. DOl: 10.2478/jas-2013-0028

Eardley, C., Roth, D., Clarke, J., Buchmann, S., Gemmill. B. (Eds). (2006). Pollinators and pollination: A resource book for policy and practice. African Pollinator Initiative. Pretoria. 77 pp.

Francoy, T. M., Franco, F. F., \& Roubik, D. W. (2012). Integrated landmark and outline-ased morphometric methods efficiently distinguish species of Euglossa (Hymenoptera, Apidae, Euglossini). Apidologie, 43, 609-617. DOl: 10.1007/s13592-012-0132-2

Francoy, T. M., Silva, R. A. O., Nunes-Silva, P., Menezes, C., Imperatriz-Fonseca, V. L. (2009). Gender identification of five genera of stingless bees (Apidae, Meliponini) based on wing morphology. Genetics and Molecular Research, 8, 207-214.

Gemmill-Herren, B., Aidoo, K., Kwapong, P., Martins, D., Kinuthia, W., Gikungu, M., Eardley, C. (2014). Priorities for research and development in the management of pollination services for agriculture in Africa. Journal of Pollination Ecology, 12(6), 40-51.

Gerula, D., Tofilski, A., Wegrzynowicz, P., Skowronek, W. (2009). Computer-assisted discrimination of honey bee subspecies used for breeding in Poland. Journal of Apicultural Science, 53 (2), 105-114.

Gonzalez, V. H. (2008). Phylogeny and classification of the bee tribe Megachilini (Hymenoptera: Apoidea, Megachilidae), with emphasis on the genus Megachile. PhD Thesis, University of Kansas, Lawrence, Kansas. 274 pp.
Güler, Y., Aytekin, A. M., \& Cagatay, N. (2006). Systematical studies on Anthidiini (Hymenoptera: Megachilidae) geometric morphometric approach. Acta Entomologica Sinica, 49(3), 474-483.

Hammer, Ø., Harper, D. A. T., \& Ryan P. D. (2001). PAST Version 2.17: paleontological statistics software package for education and data analysis. Palaeontologia Electronica, 4, 1-9.

Kandemir, I., Moradi, M. G., Özden, B., Özkan, A. (2009). Wing geometry as a tool for studying the population structure of dwarf honeybees (Apis florea Fabricius 1876) in Iran. Journal of Apicultural Research, 48(4), 238-246. DOl: 10.3896/IBRA.1.48.4.03

Klingenberg, C. P. (2011). Morphol: an integrated software package for geometric morphometrics. Molec ular Ecology Resources, 17, 353-357. DOl:10.1111/ j.1755-0998.2010.02924.x

Mac Leod, N. (2001). Landmarks, Iocalization, and the use of morphometrics in phylogenetic analysis. In: Edgecombe, G., Adrain, J., Lieberman, B. (Eds.), Fossils, phylogeny, and form: an analytical approach. Kluwer Academic/Plenum, New York: 197-233.

Michener, C. D. (2007). The bees of the world, second edition. The Johns Hopkins University Press, Baltimore. $x v i+[i]+953 \mathrm{pp}$.

Miguel, I., Baylac, M., Iriondo, M., Manzano, C., Garnery, L., Estonba, A. (2011). Both geometric morphometric and microsatellite data consistently support the differentiation of the Apis mellifera M evolutionary branch. Apidologie, 42, 150-161. DOl: 10.1051/ apido/2010048

Nazemi Rafie, J., Mohamadi, R., \& Teimory, H. (2014). Comparison of two morphometrics methods for discriminating of honey bee (Apis mellifera meda Sk.) populations in Iran. International Journal of Zoology and Research, 4, 61-70.

Oleska, A., \& Tofilski, A. (2014). Wing geometric morphometrics and microsatellite analysis provide similar discrimination of honey bee subspecies. Apidologie, 46(1):49-60. DOl: 10.1007/s13592-014-0300-7 


\section{_ FAllMMHRll EF fll. _Differentiation of Megachile based on wing shape _}

Pavlinov, I. Y. (2001). Geometric morphometrics, a new analytical approach to comparison of digitized images. Zoological Journal of Moscow, 79, 1-27.

Pitts-Singer, T. L., \& Cane, J. H. (2011). The alfalfa leafcutting bee, Megachile rotundata, the world's most intensively managed solitary bee. Annual Review of Entomology, 56, 221-237. DOl: 10.1146/annurevento-120709-144836

Rohlf, F. J. (2010). tpsDIG, Version 2.16. A program for digitizing landmarks and outlines for geometric morphometrics.Department of Ecology and Evolution, State University of New York, Stony Brook, NY, USA. Available at: http://life.bio.sunysb.edu/morph/.

Sheffield, C. S., Ratti, C., Packer, L., Griswold, T. (2011). Leafcutter and mason bees of the genus Megachile Latreille (Hymenoptera: Megachilidae) in Canada and Alaska. Canadian Journal of Arthropod Identification, 18, 1-107. DOl: 10.3752/cjai.2011.18

StatSoft Inc. (2011). STATISTICA (data analysis software system), version 10. Available at: http://www. statsoft.com.

Tofilski, A. (2008). Using geometric morphometrics and standard morphometry to discriminate three honeybee subspecies. Apidologie, 39(5), 558-563. DOl: 10.1051/apido:2008037

Williams, N. M., \& Goodell, K. (2000). Association of mandible shape and nesting material in Osmia Panzer (Hymenoptera: Megachilidae): A morphometric analysis. Annals of the Entomological Society of America, 93(2), 318-325. 